\title{
Relevância da segurança jurídica num modelo de Estado transnacional
}

\author{
Adriano Moreira Gameiro ${ }^{1}$
}

\begin{abstract}
Resumo
A atual crise do modelo de estado, sobretudo do estado de bem estar social, é grande dilema dos dias atuais. Proposta que se coloca como plausível é a de constitucionalização de blocos econômicos, como por exemplo se buscou na União Européia. Objetiva-se retratar parte da discussão sobre essa constitucionalização e mostrar como viável a formação dessa nova figura pós-nacional. Contudo inegável que essa nova figura jurídica deve ser munida de certos princípios basilares tais como a segurança jurídica, pretendendo-se demonstrar aqui a importância desse princípio para o novo modelo proposto.
\end{abstract}

Palavras-Chave: Estado Transnacional; Segurança Jurídica; Crise do Estado.

\section{Introdução}

A crise que se vivencia chamou atenção de várias áreas do conhecimento, tais como a sociologia, filosofia, economia e mais recentemente do direito. Cada uma delas foi se apercebendo do fenômeno de acordo com o surgimento de dificuldades em seu âmbito. Dessa forma a primeira a se atentar para a mencionada crise foi a economia, o que refletiu profundamente nos outros campos do conhecimento.

A referida crise se deu em decorrência dos efeitos da globalização, sendo a economia, de fato, a que mais foi atingida pelo fenômeno, de forma que os inevitáveis reflexos se alastraram pela sociedade, o que por sua vez levou a problemas jurídicos inexistentes até então.

Problemas econômicos que levaram a desestabilizar as outras áreas são, em apertada síntese, e para fins de desenvolvimento do presente trabalho, as dificuldades das políticas sociais dos Estados nacionais, principalmente nos chamados Estados de bem estar social.

As dificuldades nas políticas sociais causaram problemas de grande monta, de forma a comprometer as estruturas estatais, o que passa a ser um problema de crise do

1 Mestrando em Direito Negocial e Especialista em Filosofia Política e Jurídica, ambos pela Universidade Estadual de Londrina. Professor de Direito Processual Civil na FAP - Faculdades Apucarana. Advogado. email: portugameiro@gmail.com. 
Estado Democrático de Direito, levando a crer que o direito tem papel primordial na resolução dessas questões postas, principalmente como único meio de combater os efeitos da globalização.

Jurgüen Habermas ${ }^{2}$ é o principal defensor dessa proposta de relevância do Direito para a solução da situação de crise, conforme é possível se abstrair dos escritos de sua autoria, onde defende a criação de blocos supranacionais que possam ter força superior ou ao menos semelhantes ao mercado com suas empresas transnacionais, passando a ser essa nova figura jurídica o meio de combater a ganância do capital e amenizar assim a crise instalada.

Essa proposta foi denominada pelo Autor alemão de constelação pós-nacional em obra homônima escrita em 1998 e que teve em 2001 a sua edição brasileira (HABERMAS, 2001).

A idéia é originária, nesse sentido é de Immanuel Kant (S/D), extraído principalmente de seu texto Paz Perpétua, onde discute um projeto de paz, que é baseado entre outros fundamentos num direito cosmopolita em que cada pessoa não é integrante apenas do Estado nacional, mas é sim um cidadão do mundo. Essa idéia pode ser utilizada para defender a existência de Estados Supranacionais, tais como blocos econômicos ou constelações pós-nacionais.

Para a existência dessa espécie de Estado se faz necessária uma constituição, como a que recentemente foi discutida no âmbito europeu. Habermas foi um dentre os vários defensores da necessidade de uma constituição européia, tema este que foi debatido em

2 Habermas, alemão, um dos filósofos mais influentes da atualidade, sempre foi ousado ao discutir os grandes problemas, se destacando pela sua coragem de propor mudanças ao invés de permanecer na confortável inércia decorrente do temor de assumir nova postura. É tido como o principal herdeiro da Escola de Frankfurt, principalmente pelo fato de ter sido professor assistente de T. W. Adorno no Instituto de Pesquisa Social de Frankfurt e sucessor de Max Horkeimer na cátedra de filosofia e sociologia da Universidade de Goethe, na mesma cidade alemã. É o principal expoente da idéia de que o direito é o instrumento da sociedade para combater os efeitos da globalização que instalaram a atual crise. Destaquese que passou a acreditar de forma tão ardente no direito, que na década de 80, escreveu Faticidade e Validade, que chegou ao Brasil em 1992, onde é conhecida como Direito e Democracia. Antes dessa obra o Autor já havia escrito várias outras, dentre as quais se destacam Mudança Estrutural na Espera Pública (1961), Conhecimento e Interesse (1968), Teoria da Ação Comunicativa (1981), A Reconstrução do Materialismo Histórico (1976), Consciência Moral e Agir Comunicativo (1983), A Nova Intransparência e Discurso Filosófico da Modernidade, ambos de 1985.

Após Facticidade e Validade a produção continuou, agora diante da proposta de utilizar o direito como a saída para os problemas contemporâneos. Foram publicados, dentre outros, A inclusão do outro (1996), A constelação pós-nacional (1998), Verdade e Justificação (1999), O Futuro da Natureza Humana (2003). Facticidade e Validade, no entanto é considerada a sua obra de Filosofia do Direito por excelência. 
sua obra "a inclusão do outro", no artigo denominado "a Europa necessita de uma constituição? Um comentário sobre Dieter Grim". O mencionado texto foi uma resposta a artigo de Dieter Grimm publicado no European law journal, que era contrário à constituição européia.

Ocorre que em caso de existência de constituições supranacionais, com a criação dessa nova figura jurídica passa-se, a se discutir a prestação jurisdicional nessa sociedade e até que ponto existe a segurança jurídica nesse modelo.

\section{Viabilidade de Estados transnacionais como contraponto à crise do atual modelo estatal}

Pode ser tida como uma proposta plausível a de Blocos Econômicos munidos de constituição, todavia seria o surgimento de algo imensamente inovador e conforme historicamente se sabe, é preferível à maioria das pessoas manterem-se no atual status de crise, porém seguro, a avançar pra algo novo que ainda se desconhece a extensão das mudanças.

Desde o século XVIII se tem a discussão sobre o ideal cosmopolita, principalmente com os textos de Immanuel Kant, autor este que é tido como o principal expoente do cosmopolitismo, o que, porém, nunca havia sido muito considerado.

Nos dias atuais, de grande influencia da globalização, com as velozes trocas de informações, mais próximo se está dessa necessidade do direito cosmopolita, visto que qualquer informação cruza o planeta em segundos, causando impactos econômicos gigantescos, dessa forma nada mais justo do que se obter um sistema de direito que possa acompanhar tal metodologia e munido de meios para frear os excessos. Se o mercado de consumo, da moda, gastronomia, beleza dentre outros atingem um caráter global, e por que não dizer cosmopolita, o ideal seria o pleno reconhecimento de um direito cosmopolita. A própria globalização leva a uma tendência de cosmopolitização das mais diversas áreas, de forma que há que se pensar sim nesse direito cosmopolita.

O que se debateria com maiores rubores e exaltações seria a questão da soberania dos atuais Estados nacionais frente essa nova figura jurídica que surgiria com a formação de constituições supranacionais. Parece ser evidente que surgiria uma nova soberania do 
mencionado bloco econômico, com a modificação das soberanias estatais, de forma a adequá-las a essa nova estrutura.

Esse é ponto de extrema delicadeza em decorrência do egoísmo estabelecido de não se perder os privilégios tidos até então, de forma que os contrários a essa proposta preferem se manter com benesses numa crise a renunciar algumas mordomias para que se solucionem problemas históricos.

Nos moldes de crise atual, um Estado nacional soberano não tem de fato a sua soberania, visto que empresas transnacionais que impõem e ele as condições para que se instale nos seu território, usufruindo dos benefícios pleiteados e abandonando o Estado quando este restringe os benefícios almejados ou quando findo o prazo dos mesmos. Conforme se verifica nos dias atuais essa prática é comum, de forma que a soberania dos Estados nacionais não passa de uma ficção.

Outro fator a ser considerado é que na formação do atual modelo de Estado nacional, também foram deixados de lado alguns privilégios individuais. Segundo a teoria contratualista de formação do Estado de Hobbes, Locke e Rousseau, cada pessoa cedeu parcela de sua liberdade individual para que pudesse se formar o Estado. Não obstante a perca de parcela da liberdade os cidadãos passaram a ter a proteção estatal, de forma que a cessão alguns direitos é revertida em obtenção de novos direitos.

É plausível acreditar que se vive em uma situação de semelhança à criação dos Estados, visto que o modelo atual se encontra profundamente comprometido e para que se tenha a proteção de direitos, principalmente os individuais e sociais, seria necessário abrir mão de alguns privilégios individuais para que se atinja o fim maior de estabilização da sociedade.

Em regra são as revoluções que estabelecem novos modelos, como por exemplo no caso dos Estados Nacionais contemporâneos, que foram formados de acordo com os ditames provenientes das Revoluções Francesa e Norte-americana, conforme colocado por Habermas (2004, p. 127):

Como revela a designação 'Nações Unidas', hoje a sociedade mundial é constituída por Estados Nacionais. O tipo histórico decorrente da Revolução Francesa e da Revolução Norte-americana impôs-se em todo o mundo. Essa circunstância não é nada trivial. 
Assim, por se tratar de uma tendência mundial para a adoção de um modelo de Estado conforme a revolução que a criou, se poderia entender no mesmo sentido, porém em ordem inversa, chegando-se à conclusão então de que quando o esse modelo de Estado se mostra falido em alguns dos utilizadores desse modelo é sinal de que ele é quem está superado e não um ou outro Estado.

Mesmo que não se possa afirmar prontamente que se trata de crise do modelo estatal, mas que se verifica que vários estados estão passando por momento de crise, justificaria-se o alerta quanto a existência de um problema nos Estados Contemporâneos, visto que todos são lançados com base na mesma estrutura. Esse problema, conforme já anteriormente se dá principalmente em decorrência da globalização.

Durante pelo menos três décadas a globalização financeira e política tem colocado pressão sobre a forma de organização do Estado-nação, concebido como um Estado territorial. Esse envelhecimento coloca a questão de até quando o Estadonação vai durar e, no final, o que o irá substituir. A intervenção política de Habermas por ocasião da unificação das duas repúblicas alemãs em 1989 fala diretamente de sua posição referente ao destino do Estado-nação. A imensa sombra de Kant pode ser encontrada na declaração de Habermas de que seria um erro para os cidadãos alemães basearem sua identidade na tradição (BORRADORI, 2004, p. 63-64).

O que se objetivou demonstrar é que existe uma séria crise no modelo atual de Estado, mais especificamente no Estado do Bem Estar Social, que não consegue cumprir com suas políticas sociais frente aos obstáculos postos pela nova situação globalizada, que está totalmente desregulada juridicamente. No atual modelo a regulação que existe é apenas dos interesses econômicos, e não jurídica, de forma que se faz necessário um novo modelo, que possa regular os impulsos desses agentes econômicos.

Esse novo modelo poderia ser a proposta de formação de estruturas Supra-estatais, todavia estas somente se viabilizariam diante da prevalência de um sentimento cosmopolita dos cidadãos, que poderia fazer surgir um Direito que possa intermediar as relações internacionais, seja entre Estados, pessoas, empresas ou as três modalidades entre si. 


\subsection{Resgate do ideal cosmopolita}

Para que se leve adiante essa proposta deve ser resgatado o ideal cosmopolita kantiano, onde cada pessoa se entenda como cidadã do mundo, bem como seja tida assim pelas instituições estatais, ou no presente caso supra-estatais.

Portanto, para que se entenda a importância desta consciência de cidadania mundial, e que uma ferida a um dos países do globo traz conseqüências à todos os demais, ainda, para que se possa concluir pela viabilidade ou não de uma Constituição Supranacional ou Internacional, deve-se passar por esta retomada do ideal cosmopolita, tendo como marco inicial Immanuel Kant, chegando ao entendimento mais contemporâneo sobre tema do também alemão Jürgen Habermas.

O grande exemplo nos dias atuais sobre o assunto aqui mencionado é a Europa, que formou um forte bloco econômico, a União Européia. Cumpre salientar que o mencionado continente está um passo adiante nesse pensamento, visto que se atentaram para o problema antecipadamente em relação aos demais continentes, e isto se constata pela conhecida estabilidade dos Estados Europeus, com bons índices sociais. É claro que mesmo os países europeus começaram desde a década de oitenta a sentir alguns reflexos prejudiciais da globalização, como o desemprego, mas essas dificuldades se deram de forma mais aguda nos chamados países subdesenvolvidos. Há que se louvar a preocupação européia em tempo bem menor do que dos demais continentes e países.

A globalização causou esses dilemas nunca antes vividos pela sociedade européia, o que levou ao debate do que seria necessário para refrear seus efeitos, ou seja, conter a prevalência dos interesses mercadológicos face aos estatais.

Boa parte da doutrina européia, com vários simpatizantes políticos e mesmo na sociedade, passara a acreditar na solução desses problemas por meio de uma estrutura de maior porte, supranacionais, tais como os blocos econômicos. Não só a União Européia foi criada, como também o Mercosul, que tem o mesmo objetivo, porém não atingiu o fim inicial e menos ainda a Alça, que sequer conseguiu se formar de fato. As dificuldades de formação desses blocos já foram descritas antes, tendo como o grande empecilho o medo dos Estados Nacionais de perderem sua soberania ou ao menos parte dos privilégios que a atual situação proporciona. 
Todavia, em termos práticos, o único bloco econômico que se formou consistentemente foi a União Européia. Isso, no entanto, foi suficiente para que se produzisse um novo debate sobre se essa nova figura continental seria já uma nova figura política/jurídica, ou se para o seu pleno exercício seria necessária a formação dessa nova figura por outros meios, tais como a elaboração de uma constituição. Ao discutir sobre o tema do futuro do Estado o Professor Dalmo de Abreu Dallari (2001) estabeleceu o seguinte raciocínio:

\begin{abstract}
Assim, foram identificados três grupos de teorias que preconizam a alteração da quantidade dos Estados, ou seja, a) as teorias que afirmam que haverá um Estado mundial; b) as que sustentam que todos os Estados irão desaparecer; e c) aquelas para as quais haverá no mundo um pequeno número de super-Estados. Um quarto grupo é dos que não se referem ao número de Estados, afirmando que irá ocorrer uma transformação na qualidade dos estados existentes. Segundo os adeptos dessa teoria todos os Estados caminharão para uma espécie de "convergência", sob influencia de fatores determinantes que atingirão dimensão mundial, impondo a padronização de organização e comportamentos, chegando-se a uma situação em que não haverá conflitos por que todos terão condições semelhantes.
\end{abstract}

Não há como negar a existência de uma crise mundial do modelo de Estado Contemporâneo, o que nos leva à situação de necessidade assumir um novo modelo com a serenidade que ainda resta, ou optar por aguardar a chegada de uma situação extremada e indesejável para que se forme essa nova opção.

\title{
2.2 0 debate sobre a Constituição Européia
}

Conforme mencionado anteriormente exemplo de grande valia para o tema é o da União Européia, que teve um longo debate teórico sobre o assunto, que para fins e objetivos do presente estudo pode ser bem resumido no também já citado texto de Habermas (2004), "A Europa necessita de uma Constituição? Um comentário sobre Dieter Grimm", onde o autor concorda com o diagnóstico proposto pelo Eurocético Dieter Grimm, mas que todavia chega a conclusão diferente do mesmo, conclusão esta favorável à necessidade de uma constituição européia.

Segundo o diagnóstico de Dieter Grimm, o qual avaliza Habermas (2004), a União Européia é um ente contraditório, visto que se trata de uma organização supranacional, mas não é um Estado por não ter uma constituição própria, sendo fundamentada apenas em 
contratos de direito internacional público. Não obstante essa situação relatada, o bloco é munido de órgãos institucionais, aos quais ficam vinculados os Estados-membros. Esse segundo raciocino elevaria a União Européia a uma situação de soberania, própria de um Estado nacional.

Essas decisões reiteradas dos órgãos europeus, vinculativos aos Estados-membros passariam a ser cada vez mais constantes e com maior profundidade, o que leva à conclusão de que haveria um déficit democrático nas decisões européias, diante do fato de que a legitimação do bloco se deu por ato de vontade dos estados-membros e não da população européia.

Desse diagnóstico colocado Grimm (apud HABERMAS, 2004) acredita surgir um agravamento do déficit democrático em caso de adoção do regime federalista, que é a proposta posta. Esse agravamento se daria simplesmente pelo fato de não existir um povo europeu, esse povo estaria ainda muito ligado a sua própria nacionalidade, de forma que só seria viável uma Constituição Européia quando da existência de uma vontade política homogênea de cidadania européia, o que segundo o autor não existe na atual situação.

Já, sob o ponto de vista da mesma problemática, Habermas (2004), propõe que é possível se configurar a necessidade ou ao menos viabilidade de uma Constituição Européia. Os pontos a se debater são a incompletude das ponderações de Grimm sobre as alternativas para a redução do déficit democrático da União Européia e os meios necessários para a formação da vontade política do povo europeu.

Habermas (2004) admite os riscos existentes ao assumir a Europa uma forma de federação, todavia, considera que se trata de uma alternativa viável e que é válido correr o risco com a possibilidade de acerto à permanecer inerte apenas assistindo o agravamento da situação de crise estabelecida.

Recheada de ironia a afirmação habermasiana em desfavor da postura do eurocéticos, conforme pode se constatar do seguinte trecho de seu texto:

Mas de qualquer maneira continua aumentando a disparidade entre os crescentes poderes decisórios das autoridades européias e a legitimação precária das regulamentações européias, que continuam a adensar-se, a decisão inflexível pelo modo de legitimação exclusivamente ligados aos estados nacionais não significa simplesmente a escolha de um mal menor. Os federalistas assumem como desafio o risco (previsto, e muitas vezes evitável) de uma autonomização de organizações supranacionais. Os eurocéticos, por sua vez, conformam-se desde o início com a 
erosão da substancia democrática (inevitável, segundo eles), para não terem de abandonar a morada aparentemente segura proporcionada pelo Estado nacional (HABERMAS, 2004, p. 185).

Compreensível o entendimento de Habermas (2004), apontando que o déficit democrático surgiu no atual modelo de Estado, e que permanecer sem atuar em sentido contrário seria aguardar a decadência total do modelo que pode ter um fim catastrófico. Segundo o próprio filósofo, adotar a constituição européia não seria apenas adotar um "mal menor" mas sim apostar numa alternativa de credibilidade.

Com a desnacionalização da economia, especialmente dos mercados financeiros e da própria produção industrial, e sobretudo em face dos mercados de trabalho globalizados e em expansão, os governos nacionais vêem-se compelidos agora a assumir cada vez mais o ônus de taxas crescentes de desemprego duradouro e a marginalização de uma minoria sempre mais numerosa, a fim de atingir capacidade competitiva no cenário internacional. Caso o Estado social deva ser mantido ao menos em sua substância, e caso se deva evitar a segmentação de uma subclasse, então é preciso instituir instancias capazes de agir em um plano supranacional. Apenas os regimes de abrangência regional, como a União Européia, ainda poderiam influir sobre o sistema global, segundo uma política interna coordenada em âmbito global. [...] A meu ver, o maior perigo parece advir de uma autonomização das redes e mercados globalizados, que também colabora com a fragmentação da consciência pública. Se com essas redes sistêmicas de integração não surgirem instituições capazes de agirem politicamente, acabará por se renovar a partir do âmago de uma modernidade econômica altamente móvel o fatalismo dos Antigos Impérios, paralisante de um ponto de vista sóciopolítico (HABERMAS, 2004, p. 186).

No que diz respeito à ausência de um povo europeu, o filósofo frankfurtiano afirma que esse povo só pode se formar com a criação do Estado Europeu, e que na formação do atual modelo de Estado, optando-se pela teoria contratualista, não existia povo de nenhuma nacionalidade, e estes após a constituição dos estados foram se formando ao longo do período histórico.

Nesse sentido é possível mencionar Lourival Vilanova (2003, p. 465) que entende que "o direito é força social também, é agente que retarda e incrementa a mudança social". No caso em tela, a formação de uma ordem jurídica pós-nacional pode ajudar essa mudança social de formação de uma vontade política européia, acelerando-a ou mesmo incrementando-a, visto que conforme mencionado anteriormente o processo de cosmopolitização já se iniciou. 
O que proporcionaria esse surgimento seria a criação jurídica de uma cidadania democrática, gerando assim solidariedade entre as pessoas. Imprescindível, no entanto, o "contexto comunicacional" de reprodução de uma "autocompreensão ético-política" (HABERMAS, 2004, p. 188), e não só do regramento jurídico, afinal, a vontade política não é, e nunca foi preexistente ao surgimento de qualquer Estado nacional, o que existe é uma intersubjetividade dos agentes para a formação da vontade da maioria, para definir a vontade política.

Assim, rebatidos os argumentos eurocéticos, como feito por Habermas, passa a ser possível crer na urgência de um novo modelo estatal para a posteridade, e ainda mais, é possível imaginar que o modelo adequado é o proposto de criações de Estados Pósnacionais.

\section{Segurança jurídica nesse novo modelo estatal}

Para tratar do tema que se propõe o presente tópico necessário se faz destacar alguns pontos sobre o processo hermenêutico, que não deve ser confundido com a hermenêutica como forma de interpretação com a conseqüente aplicação do direito.

O processo hermenêutico se inicia antes mesmo do surgimento da constituição, ele não se dá no direito positivado, é anterior. Quando o legislador se reveste do poder constituinte para a elaboração da constituição é que se inicia também o mencionado processo.

O legislador constituinte, em seu papel de representante do povo, elege alguns valores jurídicos, que passam a ser de suprema importância naquela constituição ou que são os vetores do Estado que ali se forma.

De forma exemplificativa, temos como valores jurídicos da Constituição da República Federativa do Brasil a liberdade, a igualdade, a vida, a dignidade da pessoal humana, a fraternidade e a solidariedade.

Desses valores jurídicos é que surge a Constituição e por conseqüência todo o ordenamento jurídico do Estado que ali se origina. Os valores podem ser tidos como o início da positivação, com eles é possível se imaginar qual é o norte, a ideologia do Estado. 


\begin{abstract}
A Constituição provém da realidade social e sobre a realidade social se volta para modelar, i.e., dar forma às relações humanas, conferir segurança para o logro dos fins. A realidade social subjacente oferece o quadro de possibilidades dentro do qual a constituição é viável, dá-lhe o material para a forma jurídica, indica que valores e que contravalores constituem a efetiva tábua de valorações a manter. 0 direito, em seu todo, não cria os interesse, não produz os fins, não elabora as motivações dos atos, ainda que Ihe caiba, no processo social, uma função que o termo forma é insuficiente para exprimir (VILANOVA, 2003, p. 465).
\end{abstract}

Esses valores jurídicos podem se transformar em normas através de positivação de princípios, todavia a importância suprema é que eles estejam permeados por todo o ordenamento jurídico, mesmo que não de forma expressa.

No que se refere à interpretação dessas normas originadas do ordenamento decorrente dos valores é que muito embora exista a precisão dos conceitos, os termos podem não representar essa precisão, de forma que um problema lingüístico pode dificultar a interpretação legal.

A segurança é não só um conceito jurídico, como também é uma pretensão de todos os seres humanos, o que leva à própria criação do Estado, visto que este surgiu, dentre outros motivos, para garantir a segurança dos indivíduos que se encontravam no estado de natureza, isso é claro que levarmos em conta a teoria da formação do Estado do contratualistas Hobbes, Locke e Rousseau.

Assim, segundo César Garcia Novoa (2000, p. 21), a segurança é uma das principais aspirações humanas, em sua concepção de ser social. Quando se fala de segurança jurídica, no entanto, pensa-se na idoneidade do Direito para que com ele possa cada cidadão se sentir garantido e de fato seguro.

Portanto, se a segurança é um dos principais objetivos das pessoas, da mesma forma pode se dizer da segurança jurídica, que podemos ter então com um dos princípios mais importantes a serem considerados no ordenamento jurídico. A segurança deve ser encarada dessa forma como um dos fins do direito.

Ainda César García Novoa (2000, p. 22-23) entende que a segurança jurídica é elementar para a própria existência do direito, de forma que seria fundamento então para o surgimento do Estado e suas instituições. Somente o Estado poderia exalar essa segurança jurídica, com sua função jurisdicional de solucionador de conflitos, impondo sanções para quem não cumprir com o que se espera de um integrante da sociedade. 
Dessa forma a segurança jurídica nada mais é do que a segurança através por meio do direito, garantindo ao cidadão aquilo que ele mais almeja que é a tranqüilidade de que seus direitos serão respeitados e garantidos pelo Estado.

Retomando a discussão sobre a dificuldade lingüística com que sofre os textos legais, temos que a segurança jurídica entra na questão de quanto dessa dificuldade se tem lingüisticamente para o alcance do real conceito que se buscou atingir no texto da lei.

Quando o texto legal é mais preciso e restrito existe uma segurança jurídica maior do que quando o texto que se tem é mais aberto e permite interpretações diversas, sendo possível uma escala de maior e menor segurança jurídica de acordo com a linguagem aplicada na o texto legal.

Primordial, no entanto, o papel do Estado para garantir essa segurança jurídica, seja no seu papel legislativo de criação de leis claras e precisas, quanto na sua função administrativa para dar cumprimento dessas leis respeitando e proporcionando os direitos dos cidadãos ou ainda na sua atuação judiciária para garantir a melhor interpretação legal a garantir a correta aplicação da lei e conseqüentemente garantir os direitos dos indivíduos.

\section{Conclusão}

Acredita-se ter dado importância merecida à crise atual do modelo de Estado, mormente o de bem estar social, o que leva a necessidade de um novo modelo pós-nacional.

Tem-se, contudo, que conforme já defendido por Habermas, o direito passa a ter papel primordial diante da situação social que se encontra nos dias atuais, principalmente diante do célere desenvolvimento da sociedade e de fatos sem previsão legal, dentre outros problemas que existem.

O que se destaca no caso específico é o referido surgimento de um bloco europeu que não tem bem a característica de Estado nacional, mas que por sua vez tem algumas características típicas estatais.

Isso claramente é uma situação com implicação jurídica que não se encontra regulado pelo direito, mesmo por que não existe um direito supranacional preocupado com essa situação, todavia se torna imprescindível tratar do tema diante da importância do direito e da sua possibilidade de interferência nas mudanças sociais, podendo as acelerar ou as retardar. 
Essa nova constelação pós-nacional a se criar deveria tomar contorno de uma nova figura jurídica que ainda não é bem definida, todavia, objetivou-se retratar que qualquer forma que se dê a esse modelo é imprescindível que seja constante como um de seus princípios iniciais a segurança jurídica, visto que ela pode ser vista mesmo como fundamento do surgimento desse modelo como foi vista por Novoa como fundamento da atual forma de Estado.

Dessa forma, é papel do direito a organização social, proporcionando segurança aos seus cidadãos, de forma que deve ser bem equacionada a atuação do mesmo para que não gere uma situação de insegurança, o que levaria o direito a perder a sua razão de ser. Esse cuidado que se deve tomar é o dilema entre a segurança e justiça e a melhor forma de equacioná-los.

Nos Estados Democráticos de Direito a segurança jurídica é um valor essencial, diante da importância do mesmo, conforme relatado anteriormente, de forma que se faz essencial nesse novo modelo de Estado que se pretende defender, o Estado pós-nacional.

Em caso de existência de um Estado além fronteiras, como o de blocos econômicos, no exemplo citado da União Européia, é necessário que quando da atuação dos legisladores constituintes, já esteja escolhido entre os valores do novo Estado a ser criado a segurança jurídica, para que possa propiciar os direitos de seus cidadãos, o que permitiria por conseqüência, o cumprimento da promessa firmada ao longo de todo o debate teórico sobre a criação ou não desse novo modelo de Estado.

\section{Referências}

BORRADORI, Giovanna. Filosofia em tempo de terror: diálogos com Habermas e Derrida. Trad. Roberto Muggiati. Rio de Janeiro: Jorge Zahar Editora, 2004.

DALLARI, Dalmo de Abreu. O futuro do Estado. São Paulo: Saraiva, 2001.

HABERMAS, Jürgen. A inclusão do outro: estudos de teoria política. Trad. Paulo Astor Soethe. São Paulo: Edições Loyola, 2004.

. A constelação pós-nacional: ensaios políticos. Trad. Márcio Seligmann-Silva. São

Paulo: Littera Mundi, 2001.

KANT Immanuel. A Paz Perpétua: um projeto filosófico. Lisboa: Edições 70, S/D. 
NOVOA, César Garcia. El principio de seguridad jurídica in materia tributaria. Madrid: Marcial Pons, 2000.

VILANOVA, Lourival. Escritos jurídicos e filosóficos. São Paulo: Axis Mundi Ibet, 2003. v. 2. 